\title{
Síncopes de Repetición como presentación de Encefalopatía de Wernicke-Korsakov
}

\author{
Javier Lucas Pérez-Romero ${ }^{a}$, Francisco Hernández Fernández ${ }^{b}$, Ana Belén Perona Moratallac, \\ Oscar Ayo Martín ${ }^{c}$, María Elena Ortega Rubio ${ }^{d}$
}

a Residente de Medicina Familiar y Comunitaria. Unidad Docente de Albacete-Hellín.

${ }^{\mathrm{b}}$ Residente de Neurología del Complejo Hospitalario Universitario de Albacete.

${ }^{c}$ FEA de Neurología del Complejo Hospitalario Universitario de Albacete.

d FEA de Urgencias de Complejo Hospitalario Universitario de Albacete.

Correspondencia: Javier Lucas Pérez-Romero. Telf.: 657242444, e-mail: javi_lucas@hotmail.com.

Recibido el 15 de enero de 2010.

Aceptado para su publicación el 2 de abril de 2010.

\begin{abstract}
RESUMEN
La encefalopatía de Wernicke-Korsakov (EWK) es un cuadro neuropsiquiátrico agudo que cursa con la clínica clásica de paresia oculomotora, nistagmus, ataxia y alteraciones mentales. Se produce de forma secundaria a un déficit de tiamina (vitamina B1) y se da con frecuencia en alcohólicos crónicos, desnutrición, diálisis y otros desórdenes sistémicos. En ocasiones puede cursar con síntomas atípicos, lo que retrasa de forma significativa el diagnóstico.

Presentamos el caso de un varón de 61 años, no bebedor y sin antecedentes de vómitos, que consulta en varias ocasiones por una clínica inespecífica, consistente en varios episodios de pérdida transitoria de conocimiento, acompañada de malestar general y parestesias difusas. Con la evolución del proceso aparecieron los síntomas típicos de esta entidad, así como la afectación de la memoria, produciendo un síndrome amnésico de Korsakov. La ausencia de los antecedentes típicos contribuyó al retraso diagnóstico. Tras confirmar el diagnóstico, se procedió a un estudio etiológico completo, sin encontrar ningún factor subyacente. El tratamiento con tiamina parenteral produjo la recuperación parcial del cuadro. Aunque el diagnóstico de esta entidad es fundamentalmente clínico, es preferible recurrir a pruebas diagnósticas para confirmarlo, como el análisis de vitamina B1 en suero y especialmente la Resonancia Magnética craneal (RM), que muestra hallazgos característicos. Además es necesario realizar un adecuado estudio etiológico. Su diagnóstico precoz es fundamental para evitar secuelas neurológicas.
\end{abstract}

Palabras clave. Encefalopatía de Wernicke, Tiamina.

\section{ABSTRACT}

\section{Repeated syncope as a sign of Wernicke-Korsakoff Syndrome}

Wernicke-Korsakoff syndrome (WKS) has neuropsychiatric signs and symptoms and typically presents with ophthalmoparesis, nystagmus, ataxia and mental disturbances. It results from a lack of thiamine (vitamin B1) and often occurs in chronic alcoholics, people with malnutrition, on dialysis or with other systemic disorders. It may also develop with atypical symptoms, which can considerably delay diagnosis.

We present a case of a 61 year old man, non-drinker with no history of vomiting, who came to the primary care centre on several occasions due to several episodes of temporary loss of consciousness accompanied by general malaise and diffuse paraesthesia. Typical symptoms began to appear as the syndrome developed, such as memory loss producing Korsakoff's amnesia. The lack of a typical history contributed to a delayed diagnosis. After confirming the diagnosis, a complete aetiological study was conducted that did not reveal any underlying factor. Parenteral thiamine produced partial recovery.

Although diagnosis is mainly by clinical impression, diagnostic tests should be conducted such as analysis of vitamin B1 in serum and especially Magnetic Resonance Imaging (MRI) which reveals characteristic signs. An aetiological study should also be conducted. Early diagnosis is essential in order to prevent neurological sequela.

Key words. Wernicke Encephalopathy, Thiamine.

\section{INTRODUCCIÓN}

El síndrome de Wernicke-Korsakov es un cuadro neurológico carencial secundario al déficit de tiamina que se presenta con cierta frecuencia $(0,8-2,2$ $\%$ de las autopsias generales) y que se observa generalmente en alcohólicos crónicos. De forma ocasional puede observarse formando parte de otros procesos, que hay que descartar activamente, como malabsorción, vómitos persistentes, inanición, neoplasias, insuficiencia hepática, uremia, diálisis, alimentación parenteral prolongada, SIDA y tirotoxicosis ${ }^{1-4}$. 
Aunque la encefalopatía de Wernicke y la psicosis de Korsakov se consideraban clásicamente entidades distintas, hoy está aceptado respectivamente como la fase aguda y el estado residual del mismo proceso. El síndrome típico de la encefalopatía de Wernicke es la triada de alteraciones oculomotoras, ataxia y estado confusional, con un comienzo agudo. Esta clínica no siempre se encuentra de forma completa. La psicosis de Korsakov debe interpretarse como la fase crónica de este síndrome y se caracteriza por un trastorno de la memoria retentiva con relativa preservación de las otras funciones intelectuales.

La bibliografía recoge algunos casos de presentación atípica, como disfagia ${ }^{5}$, coreoatetosis ${ }^{6}$ y síndrome de Miller-Fisher ${ }^{7}$, entre otros, pero el diagnóstico final sólo se completa con el seguimiento evolutivo del cuadro. La encefalopatía debe interpretarse como una urgencia médica, ya que sin tratamiento es frecuente la evolución a coma, y la mortalidad alcanza el $17 \%$ en la fase aguda. Se trata de una enfermedad potencialmente tratable, consistente en la reposición de tiamina, así como en la corrección de los factores desencadenantes. Puede ser una buena medida preventiva el administrar 50-100 $\mathrm{mg}$ de tiamina a todo paciente alcohólico al que se le deba administrar glucosa parenteral.

Presentamos el caso de un paciente con EWK con clínica de debut consistente en síncopes de repetición, con estudio etiológico negativo, diagnosticado tardíamente gracias a la aparición del cuadro clásico y apoyado en los hallazgos de la RM y los niveles de tiamina en suero. En nuestro conocimiento esta forma de inicio no está descrita en la literatura, por lo que es necesario tener en cuenta este cuadro en el diagnóstico diferencial del síncope.

\section{OBSERVACIONES CLÍNICAS}

Paciente varón de 61 años sin hábito enólico y con antecedentes personales de cardiopatía reumática con valvuloplastia hacía 18 años, hipertensión e hipercolesterolemia. Su tratamiento habitual es AAS $100 \mathrm{mg} / 24$ horas, torasemida $5 \mathrm{mg} / 24$ horas y omeprazol $20 \mathrm{mg} / 24$ horas.

Es traído a Urgencias por su familia tras relatarles en los días previos tres episodios sincopales sin pródromos y rápida recuperación, no presenciados por testigos. El paciente se encontraba realizando su trabajo habitual, consistente en localizar puntos naturales de interés energético. En este primer episodio, en la exploración física se encontraba afebril, con una tensión arterial de 138/76 en decúbito y 142/84 en bipedestación, frecuencia cardiaca de 80 Ipm, sin soplos carotídeos, cardiacos, ni edemas. El resto de la exploración sistémica y neurológica era normal. Se solicitaron diferentes pruebas (ECG, radiografía de tórax, analítica básica con enzimas cardiacas) sin hallazgos patológicos, siendo dado de alta con el diagnóstico de probables síncopes vasovagales.

24 horas más tarde acude de nuevo a urgencias por persistencia de la clínica, añadiendo en esta ocasión sensación mal definida de malestar general y parestesias difusas. En la exploración sistémica se encontraba normotenso, sin datos de ortostatismo, mientras que en la exploración neurológica se observó nistagmus horizontal bilateral agotable e hipoestesia parcheada en abdomen y muslos sin atender a distribución metamérica. Los reflejos miotáticos estaban conservados de forma simétrica y no mostraba datos de piramidalismo. Fue interrogado por varios médicos sobre cómo sucedieron los síncopes y sorprendentemente la redacción del acontecimiento variaba cada vez que se le preguntaba. También llamó la atención su comportamiento, ya que varias veces se mostró irritable con el personal de enfermería por diversos motivos, tratándolas de manera amable minutos después. Tras ser valorado por Neurólogo y Cardiólogo de Guardia, se realizó analítica con enzimas cardiacas seriadas, TAC craneal sin contraste, electrocardiografía y radiografía de tórax, sin observarse datos patológicos. Se tomó la decisión de dar el alta y completar el estudio posteriormente en ambas consultas.

Veinte horas más tarde, de nuevo, mientras estaba trabajando, comienza con palpitaciones, vegetatosis, sensación disneica y pérdida de conocimiento, esta vez presenciada, de 3-4 minutos de duración, sin movimientos anormales, relajación de esfínteres ni periodo postcrítico. A su llegada nuevamente a Urgencias el paciente se encuentra con buen estado general y en la exploración neurológica se evidenció un nistagmus horizontal bilateral inagotable y limitación de la abducción bilateral, sensación de acorchamiento parcheado en cara anterior de tronco y extremidades inferiores. Además, aparecen datos de focalidad neurológica, con leve disinergia izquierda, dismetrías en miembros inferiores y marcha atáxica con signo de Romberg negativo. En todo momento se mostró apático y en ocasiones irritable. Con la sospecha de ictus en territorio vertebro-basilar, se realizó analítica (bioquímica, hemograma y coagulación), ECG, Radiografía de tórax, TAC con contraste, ecografía dúplex TSA y transcraneal sin hallazgos patológicos. Para completar estudio de síncope se realizó estudio cardiológico completo con Holter, ecocardiograma, ECO, dobutamina y ergometría normales. Las serologías para VIH, sífilis, borrelia, brucela, HVB y HVC fueron negativas. Estudio de autoinmunidad (ANA, ENA, ANCA, anticardiolipinas), VSG, PCR y marcadores tumorales negativos. Se inició tratamiento con clopidogrel $75 \mathrm{mg} / 24$ horas, produciéndose un empeoramiento progresivo del cuadro cerebeloso y evolucionando su estado mental hasta producirse 
una amnesia anterógrada franca. Ante la evolución tórpida se realizó RM craneal con hallazgos sugestivos de encefalopatía de Wernicke (figuras 1 y 2 ).

A pesar de que el paciente no presentaba historia de abuso de alcohol o desnutrición se constataron niveles bajos de Vitamina B1 (determinación en sangre: $13 \mathrm{pg} / \mathrm{l}$; niveles de referencia 30-95). La electroneurografía no mostró datos sugestivos de polineuropatía. Posteriormente se realizó TAC cervico-toraco-abdomino-pélvico con contraste, sin evidenciar patología alguna. Tras iniciar tratamiento intravenoso con Vitamina B1 y B6 durante 5 días, seguida de tratamiento por vía oral, el paciente mejoró paulatinamente del trastorno oculomotor, la ataxia y del trastorno amnésico. No se registraron más síncopes.

Un mes después fue valorado en consultas de Neurología, sin encontrarse alteración oculomotora ni atáxica, y quedando como secuela el trastorno sensitivo de tronco y extremidades inferiores, así como fallos mnésicos con dificultad en la retención de nueva información, sin cumplir criterios de demencia en ese momento.

\section{COMENTARIOS}

La EWK es una entidad de difícil diagnóstico ya que requiere una elevada sospecha, sobre todo en pacientes sin factores de riesgo, o que no presentan la sintomatología típica. En el caso de nuestro paciente, la ausencia de factores desencadenantes, junto con el inicio atípico, retrasaron el diagnóstico significativamente.

El déficit de vitamina B1 se puede producir tanto por una disminución del aporte vitamínico o de su absorción a nivel duodeno-yeyunal como por un aumento de su metabolismo o de su consumo. La causa más frecuente es el alcoholismo crónico, ya que el alcohol interfiere con el transporte activo intestinal de tiamina. La desnutrición, la malabsorción intestinal, y las situaciones que provocan vómitos prolongados pueden también ser precipitantes. Otras causas sistémicas más infrecuentes son el SIDA, la tuberculosis diseminada, la diálisis renal, la alimentación parenteral prolongada y algunos procesos tumorales. La dieta rica en hidratos de carbono o la administración de suero glucosado en un paciente con déficit larvado de tiamina pueden precipitarla ${ }^{4}$. Por esta razón debería prevenirse con la administración de tiamina a todos los pacientes alcohólicos que precisen glucosa parenteral.

La encefalopatía de Wernicke se caracteriza por la clínica típica de oftalmoplejia (preferiblemente VI PC), nistagmus, ataxia y alteración del estado mental. También se asocia frecuentemente polineuropatía mixta y axonal. La afectación sensorial puede tener tanto un componente periférico como central (afectación de tractos troncoencefálicos). En ocasiones puede provocar síntomas poco habituales como hipotermia, sordera neurosensorial, papiledema, alucinaciones y crisis convulsivas ${ }^{4}$. Aunque están descritos, son infrecuentes los síntomas por disfunción autonómica, como taquicardia, disnea de esfuerzo, hipotensión ortostática y síncopes, sin haber encontrado ningún caso en la literatura médica de EWK cuyo debut acontezca con síncopes de repetición.

Esta patología es una urgencia médica y requiere la administración inmediata de $100 \mathrm{mg}$ iv de tiamina, ya que de lo contrario puede sobrevenir estupor, coma y muerte. Una vez que se ha corregido la deficiencia de tiamina, no es necesario inyectar por vía parenteral, ni administrar cantidades mayores a los requerimientos diarios, salvo que haya alteraciones gastrointestinales subyacentes. Si no se establece una terapéutica adecuada puede derivar a un síndrome amnésico de Korsakov.

La amnesia anterógrada impide a estos pacientes el aprendizaje. La retrógrada se extiende hasta unos meses-años antes del inicio del cuadro, mientras que la memoria para hechos remotos permanece intacta. Este déficit de memoria les impide el aprendizaje de nuevas situaciones, por lo que son incapaces de realizar una vida social normal. Junto a este déficit de memoria anterógrada, estos enfermos presentan una alteración de la memoria retrógrada o pasada, más acusada cuanto más reciente es el hecho que se pretende recordar. En este sentido, pueden recordar algunas situaciones concretas del pasado, pero son incapaces de encadenar de modo adecuado todos los sucesos y suelen rellenar las lagunas con otros hechos inventados (fabulaciones). Éstas son típicas de los estados iniciales de la enfermedad y suelen desaparecer en estadios más crónicos.

Sólo el $25 \%$ de los pacientes que desarrollan un síndrome de Korsakoff tienen un diagnóstico clínico previo de encefalopatía de Wernicke. Sin tratamiento, la EWK empeora y es potencialmente mortal. Con tratamiento, los síntomas como la falta de coordinación y la oftalmoparesia se suelen controlar, así como impedir que la enfermedad empeore. Algunos síntomas, particularmente la ataxia, la polineuropatía y el deterioro cognitivo suelen ser difíciles de recuperar. Los pacientes con síndrome de Korsakov experimentan una recuperación total en el $25 \%$ de los casos, parcial en un $50 \%$ y aproximadamente un $25 \%$ no responde al tratamiento.

El diagnóstico de ésta patología es eminentemente clínico, aunque es recomendable confirmarlo con los hallazgos de neuroimagen y las determinaciones analíticas de tiamina y actividad de la transcelotasa, que se encuentran disminuidas. El análisis de LCR puede mostrar datos inespecíficos, como elevación 
de la proteinorraquia. Los estudios de neuroimagen son habitalmente normales. El TAC craneal no suele producir hallazgos de interés, mientras que la RM craneal es el estudio de elección. Los hallazgos característicos son la presencia de hipeintensidad periventriculares y alrededor del cuarto ventrículo ${ }^{8}$. Habitualmente no se produce alteración en las secuencias de difusión, por lo que son consistentes con edema vasogénico. Otras regiones afectadas frecuentemente son el diencéfalo y los tubérculos mamilares, que es un signo tardío.

Con esta nota clínica pretendemos recordar la importancia del diagnóstico precoz de esta patología, además de reportar una forma atípica de presentación, sólo sospechada tras comprobar un patrón evolutivo típico. Es necesario tener en cuenta la EWK en el diagnóstico diferencial del síncope y elevar el índice de sospecha en pacientes sin factores de riesgo para desarrollar carencia de tiamina. Por último, creemos necesario plantear tratamiento con suplementos de tiamina en pacientes con cuadros de afectación neurológica multifocal o cuadros confusionales sin diagnóstico evidente, sobre todo en aquellos casos en los que la neuroimagen no demuestre datos patológicos.

\section{BIBLIOGRAFÍA}

1-Garcia Carreira C. Estela Herrero J. Rivera Perpinyá G. Encefalopatía de Wernicke-Korsakoff secundario a hiperemesis no gravídica. Neurología. 2009; 24(1):74-82.

2-Qui-Ping G. Wei-Qin Z, Lu-Ning W. Wernicke's encephalopathy in non-alcoholic patients: clinical and pathologic features of three cases and literature reviewed. Neuropathology. 2006; 26:231-5.

3-Hillbom M. Pyhtinen J. Pylvänen V. Sotaniemi K. Pregnant, vomiting and coma. The Lancet. 1999; 353:1584.

4-Zarranz JJ. Neurología. $3^{a}$ ed. Madrid: Elsevier Science; 2004. p. 879-82.

5-Truedsson M, Ohlsson B, Sjöberg K. Wernicke encephalopathy presenting with severe dysphagia: a case report. Alcohol Alcohol. 2002; 37:295-6.

6-Moodley R, Seebaran AR, Rajput MC. Dystonia and choreo-athetosis in Wernicke's encepahalopathy. A case report. S Afr Med J. 1989; 75:543-4.

7-de la Cruz-Cosme F, Padilla-Parrado F, García-Casares N, Heras-Pérez JA, Sempere-Fernández J, Serrano-Castro V, et al. Síndrome de Miller Fisher como presentación de una encefalopatía de Wernicke. Rev Neurol. 2008; 46:472-5.

8-Liu YT, Fuh JL, Lirng JF, Li AF, Ho DM, Wang SJ. Correlation of magnetic resonance images with neuropathology in acute Wernicke's encephalopathy. Clin Neurol Neurosurg. 2006; 108(7):682-7.

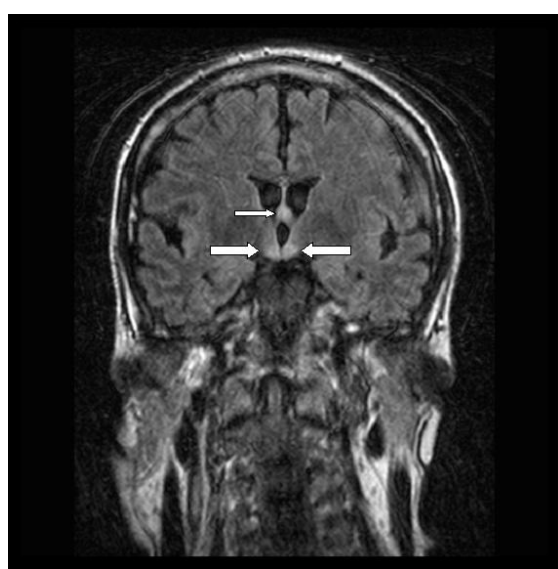

Figura 1. Secuencia FLAIR coronal en la que aparece una alteración de señal hiperintensa localizada en tubérculos mamilares y en regiones hipotalámicas adyacentes al tercer ventrículo.

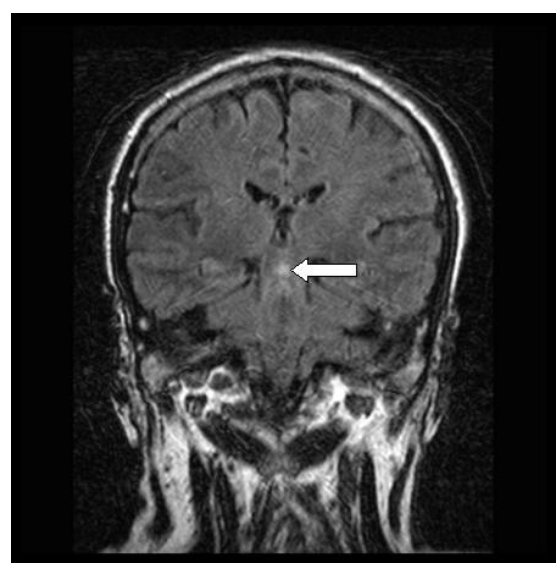

Figura 2. Secuencia FLAIR coronal en la que aparece una alteración de señal hiperintensa localizada en lámina cuadrigémina. 